\title{
Application of dermoscopy image analysis technique in diagnosing urethral condylomata acuminata*
}

\author{
Yunjie Zhang ${ }^{1}$ \\ Hui $\operatorname{Lin}^{1}$ \\ Xianbiao Zou ${ }^{1}$
}

\author{
Shuang Jiang ${ }^{1}$ \\ Xiaojuan $\mathrm{Guo}^{1}$
}

DOI: http:/ / dx.doi.org/10.1590/abd1806-4841.20186527

\begin{abstract}
BACKGROUND: In this study, cases with suspected urethral condylomata acuminata were examined by dermoscopy, in order to explore an effective method for clinical.

OBJECTIVE: To study the application of dermoscopy image analysis technique in clinical diagnosis of urethral condylomata acuminata. METHODS: A total of 220 suspected urethral condylomata acuminata were clinically diagnosed first with the naked eyes, and then by using dermoscopy image analysis technique. Afterwards, a comparative analysis was made for the two diagnostic methods.

RESULTS: Among the 220 suspected urethral condylomata acuminata, there was a higher positive rate by dermoscopy examination than visual observation.

STUDY LIMITATIONS: Dermoscopy examination technique is still restricted by its inapplicability in deep urethral orifice and skin wrinkles, and concordance between different clinicians may also vary.

Conclusion: Dermoscopy image analysis technique features a high sensitivity, quick and accurate diagnosis and is non-invasive, and we recommend its use.
\end{abstract}

Keywords: Condylomata acuminata; Dermoscopy; Urethral diseases

\section{INTRODUCTION}

Condylomata acuminata (CA) are a type of common benign hyperplastic lesions caused by the infection with human papilloma virus (HPV) on human genital areas and nearby epidermis, particularly genital mucosa, with the characteristics of high infectivity, long latent period and high recurrence rate. ${ }^{1,2}$ Dermoscopy is a noninvasive microscopic image analysis technique for observing microstructures and pigments on the skin surface in vivo, even skin structures in the lower epidermis, papillary dermis and deep dermis that are invisible to the naked eyes. In clinic, dermoscopy has an important ancillary value for the diagnosis of early malignant melanomas. ${ }^{3}$ In recent years, dermoscopy technique has also been applied in some non-tumorous and non-pigmentary skin diseases. ${ }^{4-6}$ In this study, cases with suspected urethral condylomata acuminata were evaluated by dermoscopy and dermatopathology, in order to explore an effective method for the clinical diagnosis of urethral condyloma acuminata.

\section{METHODS}

General Information

All of the 136 patients with suspected urethral condylomata acuminata were treated in our hospital between January 2013 and December 2014, including 132 males and four females. They were aged between 3-58 years old, with the average onset age of 27.7 years old; the course of disease ranged between one and six months, with the average course of disease of two months. All of their skin lesions were pink or red, millet-size to bean-size, papillary, cristate or cauliflower-like warts on or nearby urethral orifice. Each patient had one to three warts, with a total of 220 warts. Among them, 32 male patients were also diagnosed with condylomata acuminata on penis coronary sulcus, and four female patients who were also diagnosed with condylomata acuminata on the vaginal orifice or cervix. All of the cases were detected by acetic acid white test, HPV-DNA typing and dermoscopy, while some of them had dermatopathological diagnosis.

Received on 08.10.2016.

Approved by the Advisory Board and accepted for publication on 11.12.2016.

* Work performed at the First Affiliated Hospital of PLA General Hospital - Beijing, China.

Financial support: Clinical Scientific Research Supporting Fund of the General Hospital of the People's Liberation Army (special fund for the First Affiliated Hospital of the General Hospital of the People's Liberation Army) for advantageous clinical technique projects: 2015FC-TSYS-3045, 2014FC-TSYS-1014, One hundred advantages.

Conflict of interest: None.

Department of Dermatology of First Affiliated Hospital of PLA General Hospital - Beijing, China.

MAILING ADDRESS:

Xianbiao Zou

E-mail: zouxianbiao25@sina.com 


\section{Instruments and Methods}

Instruments: The dermoscope adopted was manufactured by California-based 3Gen, LLC (model: DermLiTeIIPROHR); the digital camera adopted was produced by Japanese company Sony Corporation (model: PSC-W350).

Methods: The 220 urethral warts of 132 patients with suspected urethral condylomata acuminata were divided into groups, according to the size of the warts: CA group I ( $\geq 2 \mathrm{~mm}$ ) and CA group II ( $<2 \mathrm{~mm})$. All of them were clinically diagnosed first by experienced dermatologists with naked eyes, on the basis of the morphological characteristics of skin lesions and the clinical history of the patients, and then by using the dermoscopy image analysis technique, dermatopathological diagnosis and HPV-DNA typing. Afterwards, a comparative analysis was made for the diagnostic results.

\section{Diagnostic Standards}

Clinically diagnosed cases: shall conform to the clinical manifestations, and clinicians shall judge whether they have an epidemiological history. ${ }^{7}$

Confirmed cases: shall simultaneously conform to conditions of clinically diagnosed cases as well as dermatopathological diagnosis or HPV-DNA typing.?

Diagnostic standards for dermoscopy: Under dermoscopy, the warts were papillary or flat and mostly distributed outside of urethral orifice, while a few of them were found inside the urethral orifice. The warts had characteristic blood vessels, mainly including punctate, annular, dendritic, curved, hairpin-like and polymorphic blood vessels. Condylomata acuminata are highly vascular, and one condyloma acuminatum can simultaneously have diverse forms of blood vessels (See Figure 1 for characteristics of blood vessels). ${ }^{7}$

\section{Statistical Analysis}

The experimental data was analyzed by SPSS 10.0 software and tested by $\chi^{2}$, with statistically significant differences $(\mathrm{P}<0.05)$.

\section{RESULTS}

Among the 220 suspected urethral condyloma acuminata, in CA group I ( $\geq 2 \mathrm{~mm}), 89$ samples were diagnosed as condyloma acuminata by visual observation, and 97 were diagnosed as condyloma acuminata by using dermoscopy; the chi-square test $(\mathrm{P}<0.01)$ showed

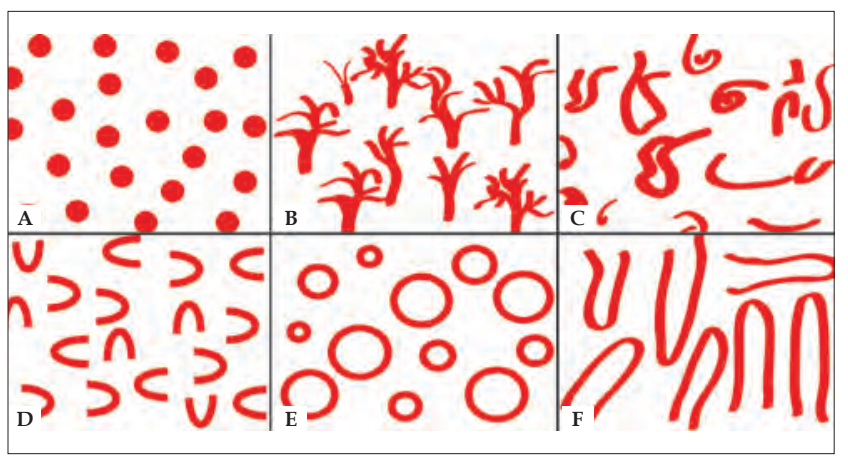

Figure 1: A: Punctate blood vessels. B: Dendritic blood vessels. C: Polymorphic blood vessels. D: Curved blood vessels. E: Annular blood vessels. F: Hairpin-like blood vessels different positive results between the two evaluation methods, namely a higher positive rate by dermoscopy examination than visual observation (Table 1). In CA group II (<2mm), 77 warts were diagnosed as condyloma acuminata by visual observation, and 119 warts were diagnosed as condyloma acuminata by dermoscopy; the chi-square test $(\mathrm{P}<0.01)$ also showed different positive results between the two evaluation methods, namely a higher positive rate by dermoscopy examination than visual observation (Table 2). The comparison between the two methods for observing skin lesions in CA group I ( $\geq 2 \mathrm{~mm})$ and CA group II $(<2 \mathrm{~mm})$, demonstrated that the visual observation showed a higher positive rate in CA group I $(\geq 2 \mathrm{~mm})$ than CA group II $(<2 \mathrm{~mm})(\mathrm{P}<0.01)$, with statistically significant differences; and dermoscopy examination showed merely slight differences between $\mathrm{CA}$ group I ( $\geq 2 \mathrm{~mm})$ and CA group II $(<2 \mathrm{~mm})(\mathrm{P}>0.05)$, with no statistically significant difference (Table 3$)$.

\section{DISCUSSION}

Urethral condylomata acuminata mostly occur on urethral mucosa. In practice, typical urethral CA skin lesions are characterized by localized single or multiple tip-size papules in the early stage, which will gradually develop into papillary, cristate, cauliflower-like or crumby neoplasms. Urethral condylomata acuminata occur at concealed areas and show no typical clinical characteristics in the early stage, which therefore may lead to missed diagnosis or delayed treatment. The diagnostic methods for urethral condyloma-

TABLE 1: Visual observation and dermoscopy examination of 98 cases of suspected urethral CA in CA group I ( $\geq 2 \mathrm{~mm})$

\begin{tabular}{lcccc} 
Group & & \multicolumn{3}{c}{ Dermoscopy examination } \\
\cline { 3 - 5 } & & Positive & Negative & Total \\
\hline Visual & Positive & 89 & 0 & 89 \\
observation & Negative & 8 & 1 & 9 \\
& Total & 97 & 1 & 98 \\
\hline & & & & $P<0.01$
\end{tabular}

TABLE 2: Visual observation and dermoscopy examination of 122 cases of suspected urethral CA in CA group II $(<2 \mathrm{~mm})$

\begin{tabular}{lcccc} 
Group & & \multicolumn{3}{c}{ Dermoscopy examination } \\
\cline { 3 - 5 } & & Positive & Negative & Total \\
\hline Visual & Positive & 77 & 0 & 77 \\
observation & Negative & 42 & 3 & 45 \\
& Total & 119 & 3 & 122 \\
\hline & & & & $P<0.01$
\end{tabular}

TABLE 3: Visual observation and dermoscopy examination of suspected urethral CA cases in both groups

\begin{tabular}{|c|c|c|c|c|c|}
\hline \multirow[t]{2}{*}{ Group } & & \multicolumn{2}{|c|}{$\begin{array}{c}\text { Visual } \\
\text { observation }\end{array}$} & \multicolumn{2}{|c|}{$\begin{array}{l}\text { Dermoscopy } \\
\text { examination }\end{array}$} \\
\hline & & Positive & Negative & Positive & Negative \\
\hline $\begin{array}{l}\text { CA group I } \\
(\geq 2 \mathrm{~mm})\end{array}$ & (n) & 89 & 9 & 97 & 1 \\
\hline \multirow{3}{*}{$\begin{array}{l}\text { CA group II } \\
(<2 \mathrm{~mm})\end{array}$} & (n) & 77 & 45 & 119 & 3 \\
\hline & & 166 & 54 & 216 & 4 \\
\hline & & $\chi^{2}=22.517$ & $\mathrm{P}<0.01$ & $\chi^{2}=0.630$ & $\mathrm{P}=0.427>0.05$ \\
\hline
\end{tabular}


ta acuminata include acetic acid white test, histopathological examination, immunohistochemistry, PCR and other laboratory methods. Specifically, acetic acid white test, although noninvasive and simple, is not a specific test for HPV infection, and may yield false positive results for some cases of chronic inflammation; ${ }^{8,9}$ histopathological examination requires collecting live tissues from patients, which is painful and invasive, and gives results after a long period of time; and in-situ hybridization technique is a sensitive, specific and reliable method for diagnosing genital warts, but can only be operated in specific laboratories, which restricts its promotion and application in clinic. ${ }^{10}$ Although the above laboratory approaches have been applied, there is still a lack of a simple, rapid, highly accurate and propagable diagnostic technique at present. Therefore, we need a new technique for diagnosing and treating condyloma acuminata.

Dermoscopy image analysis technique is a noninvasive examination technique developed in the dermatological setting in recent years, as well as a digital image analysis technique for noninvasive observation of morphological characteristics of the skin surface and lower epidermis in vivo that are invisible to the naked eyes, with an important value for diagnosing various types of skin lesions. ${ }^{11}$ Dermoscopy can be used to observe lower epidermis, dermal-epidermal junctions, papillary dermis and other skin structures invisible to the naked eyes, through lighting and optical amplification equipment, and provides an important ancillary value to clinicians in early diagnosis for skin diseases. ${ }^{12}$ Based on the principle of cross polarization, dermoscopy can eliminate the artefact from reflected light on the skin surface, with no need of interface liquid. In addition, dermoscopy can show clear original images with no direct contact with skin nor need of coupling agent, which avoids artefactual pressuring on the skin, as well as cross infection and other potential hazards caused by direct contact with skin, and thus is especially suitable for observing images of urethral mucosa and sensitive skin.

In this study, we classified the diagnosed condylomata acuminata according to their dermoscopic characteristics, and summarized common structural features and vascular characteristics of urethral condylomata acuminata under dermoscopy. In terms of the structural features, urethral condylomata acuminata are principally papillary or flat warts. Under dermoscopy, among these cases of urethral condyloma acuminata, papillary warts accounted for up to $75 \%$, which were followed by flat warts (Table 4 ). The warts were mostly observed on moist mucosa outside of urethral orifice, while a few of them were found inside urethral orifice. Because the warts were highly vascular, keratinized lesions were rarely observed. Be-

TABLE 4: Composition of different morphological characteristics of skin lesions of the 220 suspected urethral condyloma acuminata under dermoscopy

\begin{tabular}{ccc} 
& \multicolumn{2}{c}{$\begin{array}{c}\text { Morphological characteristics } \\
\text { of skin lesions }\end{array}$} \\
\cline { 2 - 3 } $\begin{array}{l}\text { Morphological characteristics } \\
\text { under dermoscopy }\end{array}$ & $\begin{array}{c}\text { Number of } \\
\text { positive cases } \\
\text { (n) }\end{array}$ & $\begin{array}{c}\text { Percentage } \\
\text { (\%) }\end{array}$ \\
\hline Papillary warts & 165 & 75.0 \\
Flat warts & 55 & 25.0 \\
Subtotal & 220 & 100 \\
\hline
\end{tabular}

sides, as condylomata acuminata are a type of hyperplastic disease and highly vascular, urethral condyloma acuminatum features positive reaction in blood vessels under dermoscopy. Among the cases we observed, those with positive reaction in blood vessels made up 99.5\% (Table 5). Under dermoscopy, the blood vessels on the urethral orifice were often deformed into punctate, annular, dendritic blood vessels, curved, hairpin-like or polymorphic blood vessels (see Figure 1). By vascular structure, these cases of urethral condylomata acuminata mostly showed punctate blood vessels and polymorphic blood vessels under dermoscopy. Urethral condylomata acuminata have abundant blood capillaries, as evidenced by the fact that both papillary warts and flat warts were found to have blood vessels, and one wart may have multiple morphologies of blood vessels (Figures 2-5).

Among the 220 skin lesions of suspected urethral condyloma acuminatum, CA group I ( $\geq 2 \mathrm{~mm}$ ) showed 89 warts diagnosed as condyloma acuminatum by visual observation and 97 warts diagnosed as condyloma acuminatum by dermoscopy, with the chisquare test indicating $\mathrm{P}=0.008<0.01$. CA group II $(<2 \mathrm{~mm})$ showed 77 warts diagnosed as condyloma acuminatum by visual observation and 119 warts diagnosed as condyloma acuminatum by dermoscopy, with the chi-square test indicating $\mathrm{P}=0.000<0.01$. On the basis of the different results of the two evaluation methods, dermoscopy provided a higher positive rate than visual observation. In visual diagnosis, clinicians usually make diagnosis by observing obvious warts and analyzing their clinical features, but always miss tiny warts that are inconspicuous to the naked eyes. In contrast, because dermoscopy can magnify warts and their structure by up to 10 times, with an incomparable superiority in observing tiny warts, it can help us indentify warts inconspicuous to the naked eyes and increase the positive rate.

Visual observation showed a higher positive rate in CA group I $(90.3 \%)$ than CA group II $(70.8 \%)\left(\chi^{2}=22.517, \mathrm{P}<0.01\right)$, with statistically significant differences. Because human eyes are more capable of identifying warts $\geq 2 \mathrm{~mm}$ but less capable of identifying those $<2 \mathrm{~mm}$, visual observation may lead to misdiagnosis or missed diagnosis, which resulted in a higher positive rate in CA group I $(\geq 2 \mathrm{~mm}$ ) than CA group II ( $<2 \mathrm{~mm})$. In contrast, dermoscopy showed no statistically significant difference in the positive rate between CA group I $(\geq 2 \mathrm{~mm})$ compared to CA group II $(<2 \mathrm{~mm})\left(\chi^{2}=0.630\right.$, $\mathrm{P}>0.05)$. Because of its polarized light and magnification functions,

TABLE 5: Composition of blood vessel characteristics of skin lesions of the 220 suspected urethral condyloma acuminata under dermoscopy

\begin{tabular}{lcc} 
Blood vessel characteristics & \multicolumn{2}{c}{$\begin{array}{l}\text { Blood vessel characteristics } \\
\text { under dermoscopy }\end{array}$} \\
\cline { 2 - 3 } & Positive & positive rate \% \\
\hline Dendritic blood vessel & 54 & 24.5 \\
Hairpin-like blood vessel & 50 & 22.7 \\
Annular blood vessel & 54 & 24.5 \\
Punctate blood vessel & 218 & 99.1 \\
Polymorphic blood vessel & 183 & 83.2 \\
Curved blood vessel & 36 & 16.4 \\
Uncharacteristic blood vessel & 1 & 0.5 \\
\hline
\end{tabular}



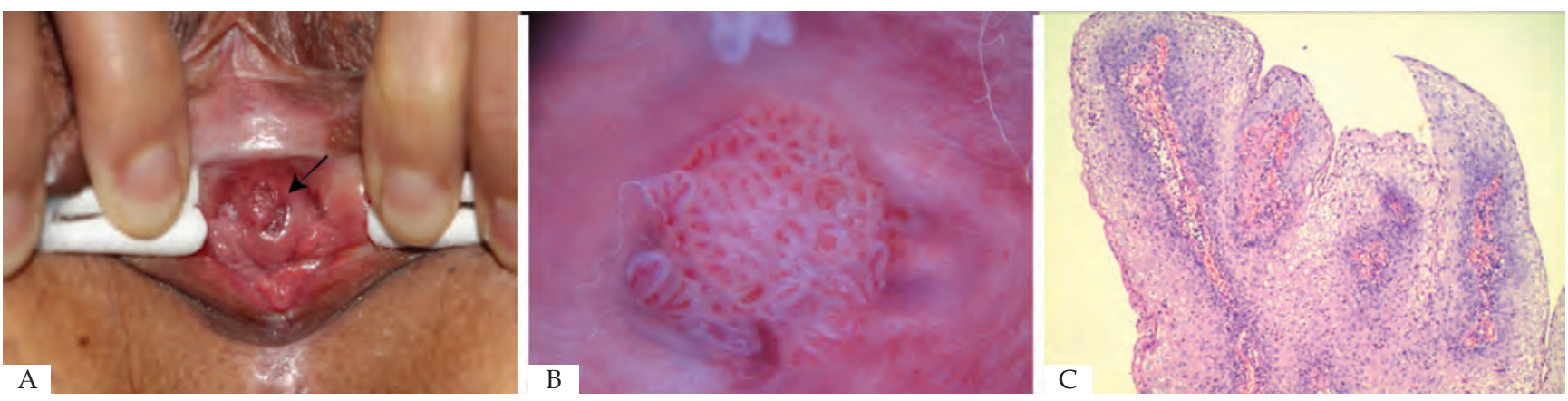

Figure 2: A. Skin lesions on urethral orifice under visual observation. B. Papillary warts, dendritic blood vessels, punctate blood vessels and polymorphic blood vessels under dermoscopy. C. Histopathological examination (Hematoxylin \& eosin, X40)
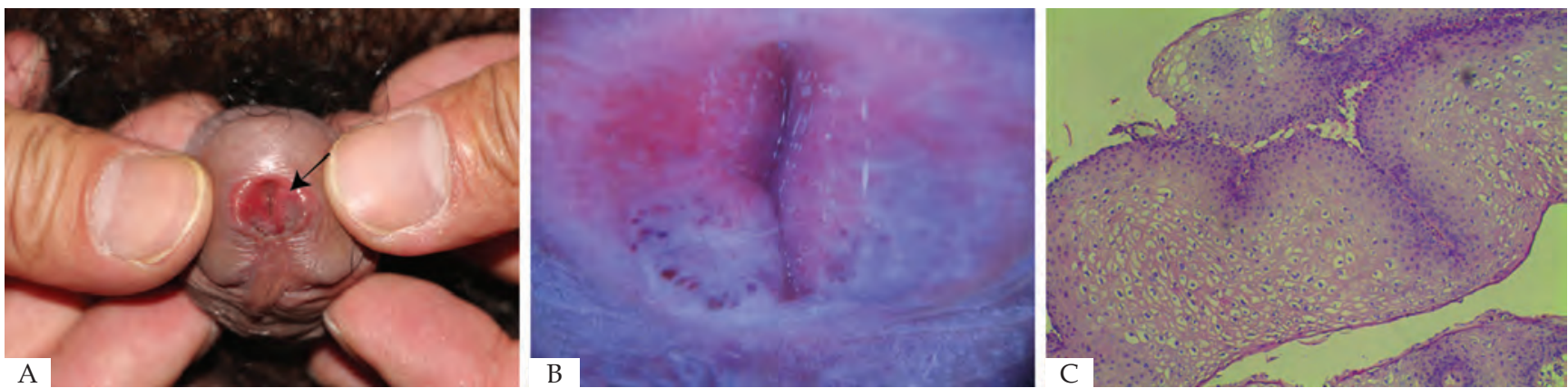

FigURE 3: A. Skin lesions on urethral orifice of a male patient under visual observation. B. Flat warts and punctate blood vessels under dermoscopy. C. Histopathological examination (Hematoxylin \& eosin, X40)
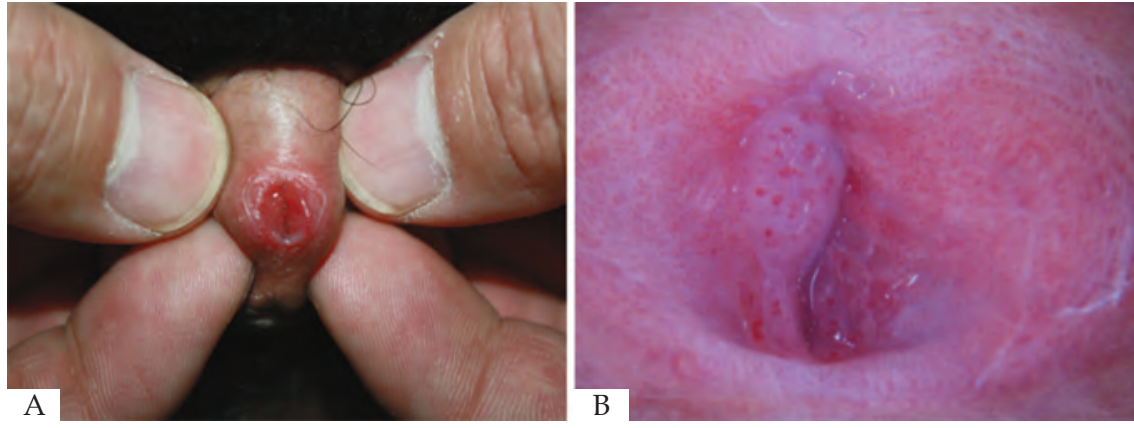

FiguRe 4: A. Skin lesions on urethral orifice under visual observation. B. Flat warts and punctate blood vessels under dermoscopy
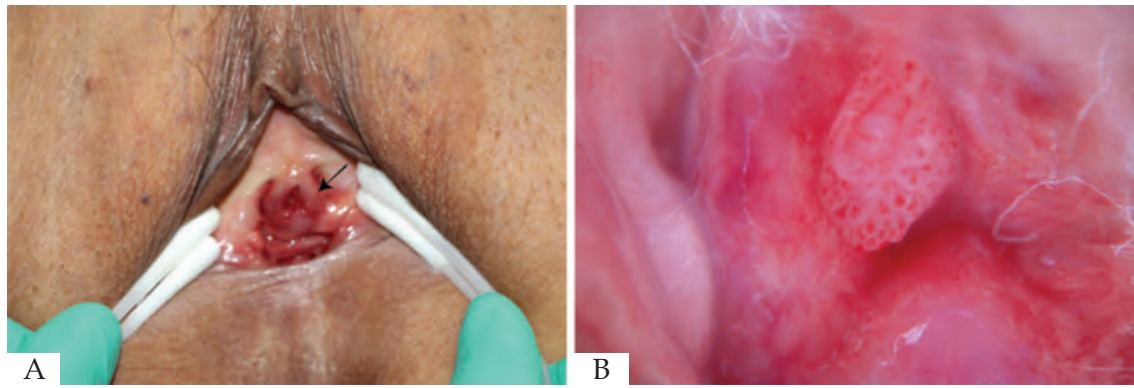

Figure 5: A. Skin lesions on urethral orifice under visual observation. B. Papillary warts, punctate blood vessels and polymorphic blood vessels under dermoscopy

dermoscopy can magnify the warts of the two groups and show clearer morphological characteristics and vascular structures, which facilitates clinical diagnosis and helps enhance the diagnostic rate. This is why dermoscopy examination showed merely slight differences between the two groups.

The cases diagnosed under dermoscopy were confirmed by
HPV-DNA typing and histopathology of part of the patients. According to HPV-DNA test, HPV-DNA type 6 and type 11 were found to be the commonest, accounting for $36.8 \%$ and $33.1 \%$, respectively (Table 6). The same one patient can be diagnosed with one or multiple genotypes of viruses, which is consistent with previous reports. During the process, patients examined by dermoscopy were much 
TABLE 6: Positive rate of the 136 patients with suspected urethral condyloma acuminata by HPV-DNA typing

\begin{tabular}{lcc}
\hline \multirow{2}{*}{ HPV-DNA types } & \multicolumn{2}{c}{ HPV-DNA typing } \\
\cline { 2 - 3 } & $\begin{array}{l}\text { Number of } \\
\text { positive cases (n) }\end{array}$ & Positive rate (\%) \\
\hline $\mathbf{6}$ & 50 & 36.8 \\
$\mathbf{1 1}$ & 45 & 33.1 \\
$\mathbf{3 9}$ & 17 & 12.5 \\
$\mathbf{4 2}$ & 16 & 11.8 \\
$\mathbf{4 3}$ & 14 & 10.3 \\
$\mathbf{5 9}$ & 5 & 3.7 \\
$\mathbf{1 6}$ & 25 & 18.4 \\
$\mathbf{1 8}$ & 22 & 16.2 \\
Negative & 6 & 4.4 \\
Other types & 23 & 10.5 \\
\hline
\end{tabular}

more compliant than those under visual observation and histopathology. In fact, because the histopathology needs a long time to prepare the sections and release the reports and is invasive, some patients are unwilling to have histopathology. On the other hand, dermoscopy is noninvasive in the urethral orifice and easy to operate, produces reports in a short period of time and allows patients to learn about their disease directly from the reports. Therefore, dermoscopy has many advantages over histopathology. Because of the lack of domestic or foreign report for the morphological characteristics of condylomata acuminata under dermoscopy, we summarized these characteristics in this study. In clinical practice, we can make clinical diagnosis for urethral condylomata acuminata according to patients' medical history, as well as structural features and vascular characteristics of urethral condylomata acuminata under dermoscopy, which boasts a higher diagnostic accordance rate than visual observation, quick diagnosis and high accuracy, and is noninvasive and thus worth clinical promotion. Aside from diagnosis, we can also apply dermoscopy in measuring post-treatment efficacy. Specifically, after the treatment of urethral condyloma acuminata, dermoscopy can be used to observe tiny skin lesions, in order to reduce the recurrence rate and enhance the clinical efficacy. Furthermore, dermoscopy leads to a reduced number of biopsies, patient pain, bleeding and the length of time for histopathology report, conducting follow-up visits and large-scale general surveys, and storing and extracting image data. Although dermoscopy is a bridge between visual observation and histopathology and has its unique advantages, the technique is still restricted by its inapplicability in deep urethral orifice and skin wrinkles; besides, various clinicians may also give different diagnoses. Therefore, dermoscopy still cannot completely replace histopathology in clinical diagnosis.

\section{CONCLUSION}

Dermoscopy image analysis technique features a high positive rate, quick and accurate diagnosis, is non-invasive, and we recommend its use. $\square$

\section{REFERENCES}

1. Arima $Y$, Winer RL, Feng Q, Hughes JP, Lee SK, Stern ME, et al. Development of urethral warts after incident detection of human papillomavirus infection in young men . J Infect Dis. 2010;202:1181-4.

2. Stanley M. Genital human papillomavirus infections-current and prospective therapies . J NatlCancInst Monogr. 2003;31:117-24.

3. Argenziano G, Soyer HP. Dermoscopy of pigmented skin lesion-valuable tool for early diagnosis of malignant melanoma . Lancet Oncol. 2001;2:443-9.

4. Paštar Z, Lipozenčić J. Significance of dermatoscopy in urethral dermatose . Clin Dermatol. 2014;32:315-8

5. Dong H, Shu D, Campbell TM, Frühauf J, Soyer HP, Hofmann-Wellenhof R. Dermatoscopy of urethral warts . J Am Acad Dermatol. 2011;64:859-64.

6. Veasey JV, Framil VM, Nadal SR, Marta AC, Lellis RF. Genital warts: comparing clinical findings to dermatoscopic aspects, in vivo reflectance confocal features and histopathologic exam. An Bras Dermatol. 2014;89:137-40

7. Yunjie Z, Xianbiao Z, Xiaojuan G, Hui L. Application value of dermoscopy in the diagnosis of condyloma acuminatum.Chin J Dermatol, 2017;7:493-496
8. von Krogh G, Lacey CJ, Gross G, Barrasso R, Schneider A. European course on HPV associated pathology: guidelines for primary care physicians for the diagnosis and management of anourethral warts. Sex Transm Infect. 2000;76:162-8.

9. Kumar B, Gupta S. Theacetowhite test in urethral human papilomavirus infection in men: what does it add? . J Eur Acad Dermatol Venereol. 2001;15:27-9.

10. Melchers W, van den Brule A, Walboomers J, de Bruin M, Burger M, Herbrink $\mathrm{P}$, et al. Increased detection rate of human papillom virus in cervical scrapes by the polymerase chain reaction as compared to modified FISH and Southern-blot analysis. J Med Virol. 1989;27:329-35.

11. Meng R, Cai R, Zhao G, Cheng X, Jiang Z, Zhou F, et al. Study on Digital Image Analysis Technique of Polari-light Dermoscopy and Discussion of Its Diagnosis for Pigmental Skin. Chinese Journal of Stereology and Image Analysis. 2006;11:122-6.

12. Meng R, Zhan G, Meng X, Jiang Z, Cai R. Study on Diagnosis for Basal Cell Carcinoma with Dermoscopy Image Analysis Technique and Its Clinical Application. Chinese Journal of Stereology and Image Analysis. 2009; 14:363-8.

How to cite this article: Zhang Y, Jiang S, Lin H, Guo X, Zou X. Application of dermoscopy image analysis technique in diagnosing urethral condylomata acuminata. An Bras Dermatol. 2018;93(1):67-71. 